daily introduction of full-sized instruments left the mucous wall of the canal, after complete cicatrisation had taken place, as supple and non-resisting to the passage of the full-sized sound as a perfectly healthy urethra. Dr. Otis finds that this condition has continued for three years after the operation, and believes this result to be due-(1st) to complete division of every fibre of the stricture, and (2nd) to the prevention of contraction of the internal wound during the process of oicatrisation.

The ultimate success of the operation must depend on the permanency of this result, and at present it is impossible to express any positive opinion on this point until we have ascertained by pathological investigation what the precise nature of the cicatricial connective tissue may be. Up to the present time I have performed this operation for stricture in the penile portion only. But change of position may require a change of practice. In the sub-pubic portion of the urethra we often meet with old strictures which are dense in structure and resist dilatation. Forcible dilatation and incision employed in such cases might readily give rise to local or general accidents of a very severe nature; and hence subcutaneous division of the contracted tissues should probably be preferred as less liable to be followed by the evil consequences just mentioned.

St. James's-place, S.w.

\section{BRAINS AND INTELLECT.}

\section{By ROBERT LAWSON, M.B.,}

PATHOLOGIST TO THE WEST RIDING LUNATIC ASYLUM.

IT is surprising, after the amount of labour that has been spent upon the subject, how little definite information has been acquired about the relation between weight of brain and extent of intellectual capacity. It is true that Cuvier, Abererombie, Dupuytren, Goodsir, Simpson, and others whose brain-weights were accurately ascertained, were found to have cerebral centres of considerably more than the average weight; but even these did not attain to the known maximum. The $64 \mathrm{oz}$. brain of Cuvier is in some respects balanced by the $65 \mathrm{oz}$. brain observed by Tiedemann and the 61 to $62 \cdot 75 \mathrm{oz}$. brains commented on by Dr. Peacock, the living representatives of which seem to have possessed no corresponding superiority over their smaller-brained contemporaries. Perhaps, indeed, if all the elements of the case were to be considered, the heaviest adult brain on record might be found to be that of a senile dement who died in the West Riding Asylum at the age of seventy. His brain was found to weigh $61 \mathrm{oz}$. Following the generally accepted principle that the brain loses weight to the extent of an ounce in each decennial period, this man's brain, after allowance has been made for physiological diminution, may be presumed to have weighed, when he was at the age of forty, no less than $64 \mathrm{oz}$. But in his case pathological supplemented physiological changes, and the more rapid atrophy which accompanies senile dementia justifies the conclusion that at the time of his maturity this man's brain may have outweighed that of the great Cuvier.

Investigations prosecuted at the West Riding Asylum by Mr. W. C. S. Clapham, and commented upon by Professor Turner,* show how fallacious any general principle would be which tended to establish a direct and exclusive relation between mere weight of brain on the one hand and capacity of intellect on the other. By a compilation of the brainweights of 705 patients who died in this asylum, Mr. Clapham showed that the average wejght of brains in the insane was little if anything below the commonly accepted average of $49 \mathrm{oz}$. in sane males and $44 \mathrm{oz}$. in adult females. And if the average brain of the resident lunatic and the obscure dispensary and hospital patient can reach a satisfactory average weight, the heary brains of the same classes of the community also contrast well with the brains of sages and the members of sane society of the general type. 'There is the $61 \mathrm{oz}$. brain of the aged dement who died in this asylum;

* West Riding Asylum Medical Reports, vol, iii, 1873. the $60 \mathrm{ox}$. brain of a boy of fifteen, as cited by Professor Turner; the brains referred to by Dr. Peacock and mentioned above, ranging in weight from 61 to $62.75 \mathrm{oz} . ;$ and the numerous instances in the records of the West Riding and other lunatic asylums in which male brains are noted as weighing from 58 to $61 \mathrm{oz}$, and female brains from 50 to $56 \mathrm{oz}$. When the brain-weights of men who have earned fame in science, philosophy, or politics are directly compared or contrasted with those of men whose lives have been mute and inglorious, and even despicable, they are by no means so striking as when quoted by themselves. Thus-

Brain-weight of Dr. Chalmers, $\quad 53 \mathrm{oz} . \ldots$ Lunatic, $58 \mathrm{oz}$.

$$
\begin{aligned}
& \text { " Daniel Webster, } 535 \quad \ldots \quad \text {, } 58 \\
& \text { " Sir J. Y. Simpson, 54 } \quad \ldots \quad \text { " } \quad 58.5 \\
& \begin{array}{lllll}
\prime \quad \text { Goodsir, } & 57.5 & \ldots & \text { " } & 59.5 \\
\text { A bercrombie, } & 63 & \ldots & \text { " } & 60.5
\end{array} \\
& \begin{array}{lllll}
\text { " Abercrombie, } & 63 & \ldots & , & 605 \\
\text { Cuvier, } & 64 & \ldots & , & 61
\end{array}
\end{aligned}
$$

The weights of brain in Abercrombie and Cuvier cannot be directly balanced by any West Riding Asylum brains, but could be fairly contrasted with the 63 and $65 \mathrm{oz}$. brains observed respectively by Reid and Tiedemann. The brains also of female lunatic patients, when placed in the balance, are not necessarily found wanting. Mr. Clapham's figures show that amongst rather more than 300 insane women, brains were found weighing from 50 to $56 \mathrm{oz}$., and which, in acknowledged proportion, were equal to male brains of $55,58,60$, and $61 \mathrm{oz}$. Relatively speaking, these insane women had more brains than Chalmers, Webster, Simpson, Goodsir, Lord Campbell, and many others adduced as illus. trations of the statement that great size of brain usually accompanies great intellectual capacity. Similarly with regard to criminal lunatics: though the average weight of brain amongst a single dozen of these, examined by Dr. Orange of Broadmoor, is an ounce and a half under the general male average, there are in that limited number two brains which exceed that of Chalmers in weight, and one which outweighs those of Chalmers, Daniel Webster, and Simpson, and is within half an ounce of being equal to that of John Goodsir.

But if the occasional oceurrence of very heavy brains amongst men of great ability is no proof of the general proposition that all men of great intellectual capacity have heavy brains, neither is the fact that very heavy brains are found amongst lunatics proof that large brains are not, coeteris paribus, characteristic of the capability or existence of great mental power. The occurrence amongst men of great ability, or even genius, of instances in which lunacy may be regarded as having tinged the products of their minds, and in some instances impregnated their works with the impassioned fervour which alone ennobles them, shows that such an assumption would be altogether gratuitous. Such men, for instance, as Byron, Shelley, Poe, Lamb, Cowper, and, in some degree, Dean Swift, have given evidence in their writings and their lives of such a taint. From the time of St. Paul the fervid apostle, Lucretius the philosophic and Dante the melancholic poet, down to that of Dr. Johnson, the apostle of common sense, the men are numerous who have had ascribed to them the combination of much learning and more or less madness; and even in more recent times a veil lies over the lives of many of our great men and great women, which, if it were to be removed, would show that some of those who have charmed us with their brilliancy and helped to mould us by their power have not been exempt from the occasional or constant workings of the genius of insanity. Every day the observation of the poet that great wit is nearly allied to madness gains a wider and more practical acceptance. So much is this the case that Dr. Wilks, in a very thoughtful and suggestive paper in a recent number of the Journal of Mental Science, venture to make the statement that probably " it is the insane element which imparts what we call genius to the human race, the true celestial fire; and thus it is that the madman has been called inspired and thought to have in him a touch of the divinity." $\dagger$ Though it is fearful to think of the propagation of a race tainted with insanity, yet, says Dr. Wilks, "it does not follow that an infusion of the insane blood may not be desirable. I think it might easily be shown that such infusion has given genins to a whole family; it has

* Annual Report, Broadmoor Criminal Lunatic Asylum, 1873, p. 57.

+ The Study of the Human Mind. By Samuel Wilks, M.D. (Journal of Mental Science, Jan. 1875.) 
leavened the whole mass." Dr. Maudsley holds the same opinion; and, however painful the observation may be, there can be little doubt that it is marvellously true.

A pauper lunatic asylum is a very unfavourable field for judging of the relation between brain-weight and intellectual capacity. Imperfections of education in the patients with which one has to deal prevent the manifestation of intellectual capacity. The commonplace and the potentially superior mind meet on the common standpoint of mediocrity. The reiteration of uneventful and almost stereotyped histories frustrates the scientific observer in his endenvour to detect in the recorded lives of large-brained pauper lunatics any prior evidences of superior power in developing or utilising the circumstances of a healthy social existence. Still, it sometimes does happen that one can determine, by an inquiry into the history of the insane, that men with unusually large brain-weights were during the sane period of their existence characterised by greater mental vigour and higher intellectual capacity than their station in life would have led one to expect. Such a case occurred in this asylum shortly after the compilation of the statistics of Mr. Clapham and the observations of Professor Turner.

A. B-, a weaver aged forty-five, was admitted last year on account of a first attack of mania. In the form of admission it was stated that the patient had been talking incoherently upon religious subjects and the making of wills; that he was restless, and, when restrained, violent; and that he was indecent in his acts. He was not epileptic.

About six weeks before admission the patient became depressed. This depression lasted for about a month, and was succeeded by excitement. He became incoherent and at times obscene in his conversation, and violent to those about him. He attempted to bite those who were guarding him, and during the night left his bed and caused annoyance to his neighbours. Having become quite unmanageable, he was certified for removal.

Two cousins had been insane, and one of them had been treated in an asylum. It was satisfactorily determined that the patient had been an unusually sober and steady man, even though his symptoms on admission resembled in some particulars those characteristic of the prostration following upon excessive drinking.

A searching examination into his history led to the determination that he had been regarded by his fellow-townsmen as a very intelligent man. He was very fond of reading, and devoted special attention to the study of religious subjects. He had written a good deal, mainly on religious topics; and showed a remarkable memory, which was chiefly manifested by the repetition of large portions of any sermon which he had heard. He had an ambition to qualify himself as a preacher and engage in missionary work. He was also a recognised leader in politics, was regarded as the leading man in the agitation relating to the establishment of the School Board in the town where he resided, and during all political contests was relied upon as an influential agitator in the Liberal interest. He appears to have been much addicted to controversy, and the excitement of argument is said to have induced frequently a violent pain on the top of the head, which compelled him to abandon for a few minutes his share in the discussion. For eight or nine years he had suffered from headaches, which were much intensified by reading.

On admission he was very restless and excited. $\mathrm{He}$ talked incoherently, and was very anxious to make a long statement about some conveyance of property, payment of succession duly, and indemnification for losses. He refused food, and at night lost sleep under the influence of delusions; he also had hallucinations of smell, delusions of a prurient nature, and a further delusion that his head or body had been changed during the progress of some surgical operation which he had undergone. His tongue and all his muscular movements were tremulous. With the exception of incontinence of urine and disorder of the alimentary system, he had no bodily ailment. His temperament was sanguineous. When admitted, his weight was $168 \mathrm{lb}$., and his height $5 \mathrm{ft} .9 \mathrm{in.}$ A fortnight afterwards he showed signs of inflammatory action affecting the right side of the chest, and in another week succumbed to an attack of double pleurisy with effusion.

On post-mortem examination, it was found that the body was well nourished, but the limbs were somewhat œdematous. The skull-cap was capacious, but normal in thickness and density, and symmetrical. During the removal of the brain little or no fluid escaped. Beyond the existence of a limited amount of subarachnoid extrarasation of blood into the sulci, the brain appeared to present nothing abnormal at the same time the sulci were narrow. The pia mater was thin, and on that account stripped with difficulty; but there were no adhesions. The weight of the whole brain was $61 \mathrm{oz}$. The convolutions were plump and well differentiated, especially in the second frontal tier, and showed no sign of having been compressed. The measurements of the head were: from root of nose to occipital protuberance, 15 in. from meatus auditorius, left to right, $15 \frac{1}{2} \mathrm{in}$.; circumference round middle of forehead and over occipital protuberance, $23 \frac{1}{2}$ in.; diameter of cranial cavity from before backwards, $6 \frac{7}{5}$ in. ; ditto across, $5 \frac{3}{8}$ in. A large quantity of serous fluid was found in each pleural cavity, and a patch of grey hepatisation occupied part of the lower lobe of the right lung posteriorly.

Observations. - The patient in this case was known by his associates to have been a man of superior intellect. His brain-weight after death proved to be greater than the external measurements of the head might have led one to anticipate. Amidst the evidences of more than ordinary mental capacity, he occasionally showed signs of the existence of some unhealthy intra-cranial condition. Occupations involving a congestive state of the cerebrum induced violent coronal pain, which was alleviated only by his desisting from the study or the discussion which had induced it. Ultimately he fell into a short depressed condition, which was followed by an attack of acute mania and the development of fatal physical lesions. On post-mortem examination his brain was found to be $12 \mathrm{oz}$. more than the average weight in adult males. That the large size of the brain was not due to effusion into the ventricles was shown by the very limited quantity of fluid which escaped on removal and section. That it was not due to any recent condition of hypertrophy was evident by the plump appearance of the convolutions and the absence of all signs of compression. On the other hand, the plumpness and the complexity of the gyri, and the previous definite history of the patient's proclivities and accomplishments, go to show that he had normally a heavy brain, which, in his limited sphere, he exercised in such a manner as to secure a character for intellectual superiority.

Similar cases are of not infrequent occurrence.

M. W_- aged thirty-six, was admitted in to the Durham County Asylum* in July, 1873. His mind had been deranged for about four years previous to that date. On admission be was epileptic. He was incoherent in his talk, showed great loss of memory, and was very inconsistent in bis statements, affirming that he had children of the age of thirty-five, though he himself was only thirty-six years old. He was restless at night, left his bed, roamed about the house, and was unable to return to where he started from. He had attacks of excitement. During his residence his condition was that of dementia. He had occasional epileptic fits and several attacks of syncope. Before and after the fits he was very stupid. On admission his physical condition was fairly good. He died in June, 1874, and the cause of death was fatty degeneration of the heart and bronchitis. The weight of his brain was $60 \mathrm{oz}$.

This patient had had little early training, and in his youth was a steady, hard worker, who devoted his leisure hours to the acquirement of elementary education. He was born in the very lowest ranks of society, and by perseverance and industry advanced himself to a condition of comfort. He commenced life as a labourer, but soon raised himself to the position of a rag and bone merchant, with a horse and cart of his own; and finally, by industry, economy, and ability, was able to start in business as a marine store dealer. He saved 2600 , and brought up his family comfortably. It appears that he retained his mental acuteness till he discovered almost simultaneously that his wife had become a drunkard and squandered all his hard-earned savings, and that his daughter had abandoned herself to public prostitution. These discoveries threw him into a state of excitement, and at that time he had his first epileptic fit. The fits recurred at rare intervals, and were isolated. They were preceded by stupor and giddiness.

* For the particulars of this and the following case $I$ am indebted to the kindness of Dr. Smith, medical superintendent, and Dr. Wallis, late assist medical officer, Durham County Asylum. 
While at the Durham Asylum he was quiet and demented. He died after a few days' illness.

J. H- was for the second time admitted into Durham County Asylum in July, 1862. He was suffering from recurrent mania. The patient was a member of a family characterised by good physical and mental development. He gradually sank into a condition of consecutive dementia, but continued to manifest considerable ability, especiaily in making calculations. He wrought out complex arithmetical problems mentally, and with great readiness and correctness. In early life he was an agricultural labourer, and pushed his way on so steadily and showed such special capabilities for the work that he secured the appointment of road surveyor of a district. $\mathrm{He}$ was regarded by all who knew him as a man of great original ability. $\mathrm{He}$ never reached any great amount of dementia, and within three months of his death gave clear evidence regarding an assault of which he had been a witness. He died on the $25 \mathrm{th}$ of June, 1870. His brain weighed between 60 and $61 \mathrm{oz}$. The condition was one of atrophy, associated with atheroma of the cerebral arteries.

It is worthy of renewed notice that, in the brain referred to in the first case recorded in this paper, the complexity of the convolutions is quite as characteristic as the unusual weight. As I have not seen the brains referred to in the last two instances, I am unable to say what was the extent of the differentiation of their gyri ; but the general principle that multiplicity of gyri is more characteristic than large size as a gauge of intellectual capacity mas readily be accepted as a safe one.

West-Riding Lunatic Asylum, Wakefield.

\section{DEATH FROM THORACIC ANEURISM. BEPORTED BY}

SURGEON HENRY C. WOODS, M.D., R.N.

(Communicated by the Director-Gerreral of the Mepical Departuram OF THE NAVY.)

THE previous history of this most instructive case has been already fully reported, and further published in THE LANCET of July 5th, 1873; a brief résumé is, therefore, only given.

J. F-, aged thirty-five, a private in the Royal Marine Light Infantry, with now fourteen zears' service, was admitted on the 3rd of June, 1872, with a small left femoral aneurism immediately below Poupart's ligament. He was a spare, rather aged-looking man, with dark hair, sallow complexion, and slight arcus senilis. He had on the 20th of May first noticed pulsation in the groin, no cause being traceable. Intermitting digital pressure, and subsequently persistent for forty-eight hours, and acute flexion, failed to procure consolidation. On the 20th of August the anterior iliac was secured by Fleet-Surgeon John Elliott, R.N. (then in charge of the hospital), a carbolic-gut ligature being used, and the ends cut short off. The wound was dressed with carbolic solutions, \&c. On the 23rd, a slight erysipelatous blush appearing, the dressings were removed. The wound appeared to be healing by the first intention. Free suppuration was, however, afterwards set up. On the 25th a faint pulsation was detected, and soon became confirmed; the sac then steadily and slowly enlarging. The gut had evidently absorbad and permitted the circulation to be re established. Pressure with a Carte's tourniquet (which proved successful in a similar case at the same time under treatment), flexion, and distal pressure were again tried, and failed. On the 26th of November the artery was a second time secured by Flett-Surgeon Elliott, who this time made use of a double well-carbolised hempen ligature, leaving one end hanging out of the wound. The operation was tedious, the tissues being firmly matted together. The peritoneum was with difficulty detached, and twice unavoidably opened into; vomiting occurring, with escape of small intestine and omentum. The ligature did not separate until the 4 th of January, and the wound then closed. For a few days from the 19 th of December there were grave typhoid symptoms, with local erysipelatous action. The pulsation ceased from the date of operation, and the sac became consolidated, being firm and of the size of a walnut when discharged to light duty on the 2nd of April. There was, however, great weakness and bulging of the abdominal wall over the site of the cicatrices.

He was employed as a cook in the provost cells, and remained at duty until the 11th March of this year, when he was admitted, and remained under treatment until the 27th March, for bronchitis; no further symptoms being noted by Staff-Surgeon Fisher, R.N., under whose care he more particularly was.

On the 23rd June he again applied for relief, having, as it has been subsequently ascertained, suffered from pain in the left shoulder and arm, with gradually increasing dys. pnoa. On admission, this was urgent; the respiration loudly erepitant, with sonorous rhonchus over the whole chest, particularly over the upper portions; the hearto sounds were scarcely audible, and there was loud churning over the upper portion of the sternum; the pulse was excessively feeble and frequent; the face livid, with coldness of the extremities. No pulsation was visible over the sternum or the neck; the venous system was, however, engorged. Decubitus was found to be most comfortable on the side in a semi-recumbent position. Beef-tea, port wine, brandy, mixtures of ammonia (carbonate and chloride), squill, ether, ipecacuanha, \&c., were given to arrest expectoration; the sputa being viscid frothy mucus, and latterly slightly purulent. Locally, turpentine and simple fomentations, poultices, and a blister to the left side. The radials were synchronous. On the 24 th a gritty pericardiac friction was detected over the heart's apex. The dyepnœa became increasingly urgent until death, on the 29th June, at 1.50 A.M. Pain was never complained of, but to another patient he said that "he could almost reach something in his throat with his finger which seemed to prevent his breathing." There was never any dysphagia.

Post-mortem examination, June 30 th, 11 A M. - Body attenuated; rigor mortis present. On removing the sternum a large aneurism of the ascending aorta was disclosed, the anterior wall being closely adherent to, and in part formed by, the sternum, from a point level with the lower border of the first to midway between the third and fourth cartilages, the bone being in part eroded. The aneurism was $4 \frac{1}{2}$ in. +4 in. in diameter, extending to and involving $\frac{s}{4}$ in. of the innominate artery anteriorly, and inferiorly overlapping the base of the heart. On opening it up, a large yellow fibrinous clot was found nearly filling it, and lying in black coagula, which further extended through a small valve-like rupture at the left base of $\frac{1}{3}$ in. into the pericardium, the heart being also encased in it. On the right side the sac was found to be thickened to $\frac{x}{2}$ in. by layers of fibrin, but on the left was thin; at the back of the aneurism, and apparently almost lying in it, from the walls overlapping on either side, was the aorta, with an oval opening of $1 \frac{1}{2}$ in. in length by $\frac{1}{8}$ in. transverse diameter, the edges rounded and indurated, giving almost the idea of the upper open end of the larynx. The heart was contracted and healtby, with a thin covering of fat, and the valves normal; about $4 \mathrm{oz}$. of sanious serum escaped from the pericardium on opening it up, and the clot there weighed $8 \mathrm{oz}$. The lungs were congested, but healthy in structure, abundant sanious frothy mucus welling out on section. The left division of the trachea appeared rather small. The aorta from the heart to the coeliac axis was unduly dilated, particularly at the latter point; and, on section, patches of atheromatous change were found, but no ossific deposit.-Abdomen: Viscera bealthy; the liver slightly nutmeg in character, weighing $3 \mathrm{lb} .10 \mathrm{oz}$. A portion of the small intestine and two loops of omentum were found firmly adherent to the abdominal wall at the seat of operation. The left internal iliac was considerably smaller than the right, and obliterated about 2 in. from Poupart's ligament. The internal iliac correspondingly increased in size, the collateral circulation being carried on by it. From the point of ligature the artery could be traced as a cord to the aneuriamal sac in the groin, which was firm, of the size of a small walnut, and filled by a firm, dark, fibrinous clot, which was readily enucleated, the artery becoming pervious almost immediately below. The aneurism involved and occluded the "profunda" at its origin; the circumflex was enlarged, and carried on the circulation with it.

Walmer, 